\title{
Trading Behaviours Analysis in an Artificial Stock Market
}

\author{
Pan Fuchen ${ }^{1,2, *}$, Li Lin ${ }^{3}$ \\ ${ }^{1}$ College of Science, Dalian Ocean University, Dalian, China \\ ${ }^{2}$ College of Basic Education, Dalian University of Finance and Economics, Dalian, China \\ ${ }^{3}$ Department of Technology, Dalian Radio and TV University, Dalian, China
}

\section{Email address:}

pancf@dlou.edu.cn (Pan Fuchen), litiptop@163.com(Li Lin)

${ }^{*}$ Corresponding author

\section{To cite this article:}

Pan Fuchen, Li Lin. Trading Behaviours Analysis in an Artificial Stock Market. Journal of Finance and Accounting. Vol. 6, No. 2, 2018, pp. 69-75. doi: 10.11648/j.jfa.20180602.13

Received: March 8, 2018; Accepted: March 19, 2018; Published: May 23, 2018

\begin{abstract}
In this paper, we study trading behavior of five different populations with different trading strategies in the framework of an artificial stock market. Insiders who know accuracy time and quantity of inflow cash enter into market and trade with others, which increase difficulty to get more profit for non-insiders. A new clearing mechanism that matches price in order is mentioned. Simulation results show that trading strategies yield different results. It is noticeable that insider can easily get more profit in short time due to prior information.
\end{abstract}

Keywords: Trading Behaviours, Artificial Stock Market, Prior Information, Market Clearing

\section{Introduction}

The world of business is not only complex and competitive but contains various multiple tasks. Most of the business organizations today are using information technology (IT) application to improve their operational efficiency, product and service quality [1]. Over the last decade, a fairly large literature has explored the properties of complex financial systems. Artificial stock market (ASM) is the realization of complex financial market. The self-adaption, evolution, nonlinear, bounded rationality are introduced. Computer simulation technology is used to obtain micro-interpretation behind macroscopic heteromorphism of financial market, creating a new field of experimental finance [2-4]. Investment and output are affected by individual net worth in the presence of a financial friction at the firm level [5]. Cipriani, M., \& Guarino, A. discuss a structural model of herd behavior in financial markets [6]. Hazem Krichene and Mhamed-Ali El-Aroui present an artificial order-driven market able to reproduce mature and immature stock markets properties in the case of a single traded asset, which is designed to simulate characteristics of immature stock markets by reproducing their stylized facts related mainly to information asymmetry and herd behavior. [7] Tedeschi et al. study the herding effect through a dynamic network structure: the communication structure allows rises and falls of Gurus over time [8]. Mizuta et al. finds that price limits, blanket short selling regulations, and uptick rules can prevent overshoot and make the market efficiency during a bubble collapse, but the last two will make the market overpriced under the normal situation [9] Xuan Zhou and Honggang Li simulate trader behaviors and analyze the influence of the leverage trading on liquidity, volatility and price-discovery efficiency. Difference from the most studies, they analyze the issue by changing the leverage ratio, instead of introducing some short selling regulations, such as price limits, blanket short selling regulations, and uptick rules [10]. Anand et. al. proposed that structural changes in an economy or in financial markets could result because of agents' adoption of rules that appear to be the norm in their surroundings [11]. In another recent work proposed a model called increasing decreasing linear neuron for high-frequency stock market prediction [12]. Hafezi, R. et al. propose a new intelligent model in a multi-agent framework called bat-neural network multi-agent system (BNNMAS) to predict stock price [13]. Regarding agent-based simulations, an option market model based on the Black-Scholes formula was studied [14]. Xu et al. proposed an agent-based computational model to study multiple assets with spot-futures arbitrageurs in an attempt to reproduce the statistical properties of real Chinese markets 
[15]. In artificial stock market, both micro level investor behavior as well as macro level stock market dynamics are research fields that are full of unresolved research questions and therefore enjoy a strong interest of scholars and practitioners alike $[16,17]$.

It is obvious that different investors use different investing behaviours that are, at least partially, responsible for the time evolution of market prices. Though no agents owe supernatural ability to forecast price, it is more timely and accuracy to act on transaction for some agents with insider information.

In this paper, we present a simplified model of artificial stock market to discuss the trading behaviors of the traders. The market consists of five types of trade populations, which are random traders, chartist traders, contrarian traders, fundamentalist traders, insiders. It is crucial for all investors to obtain the prior information, which can guide their investment strategies. In our model, insider traders play against other traders: only insiders have the priority of obtaining prior information, other traders are trading with their respective trading rules.

Firstly, we describe the formation of artificial stock market including trade populations, interaction rules, and so on. Secondly, we present experimental results on the price process, which provides a possible interpretation of results. The interactions among various populations are enough to generate these complex outcomes. In the next section, the model will be described in detail.

\section{Traders' Population in the Artificial Stock Market}

We built an artificial stock market with autonomous agents using simple decision rules based on imitative and fundamentalist behavior. Traders who buy and sell a risky asset in exchange of cash are segmented into five population-types, depending on their respective trading behaviour: random, chartist, contrarian, fundamentalist, and insider. The decision-making process of each trader is constrained by the limited financial resources and influenced by the volatility of the market. The trading mechanism of the ASM is based on a realistic auction-type order matching mechanism that allows defining a demand-supply schedule. The number of agents engaged in trading at each moment is a small fraction of the total number of agents.

Suppose that there are $N$ gents in the whole market, $N=\sum_{i=1}^{5} N_{i}$, where $\mathrm{N}_{\mathrm{i}}$ represents the number of each population-type. At every discrete trading moment $t$, a trader $\mathrm{i}$ holds an amount $\mathrm{c}_{\mathrm{i}}(\mathrm{t})$ of cash and an amount $\mathrm{s}_{\mathrm{i}}(\mathrm{t})$ of stock.

\subsection{Random Traders}

Random traders are characterized by very simple trading strategies: no intelligence and random trading constrained by limited resources and past volatility. At the beginning of the simulation $(t=0)$, random traders operate in the market; each random make decision by comparing agent Prob To Act (the probability of placing an order) with a stochastic number range from 0.0 to 1.0: if agent Prob To Act $<$ a stochastic number, do nothing; if agent Prob To Act $>$ a stochastic number, buy or sell randomly, the actual quantity is chosen randomly in a range from 1 to max Order Number (the max buying or selling quantity in each order placed by an agent) [18].

\subsection{Chartist Traders}

The chartist trader is a trend follower who makes decisions depending on the trend of past prices. The chartist trader speculates that, if prices are rising, they will keep rising, and if prices are falling, they will keep falling. Chartist traders mutual effect in the market.

At each simulation step, a chartist trader places an order with probability 0.02 , who known as strategy for those who monitor market trend for certain history referred horizon - this method also known as moving average (MA).

Agent sells if MA value $m_{t}(h)=\frac{1}{h} \sum_{i=t-h}^{t-1} p_{t}$ computed with $\mathrm{h}$ time horizon is larger than the price: $p_{t}^{+}=p_{t}+p_{t} \varepsilon$, where $\varepsilon \in(0,1)$ as input parameter. They will buy if the value of MA parameter is below the price: $p_{t}^{-}=p_{t}-p_{t} \varepsilon$.

The quantity that each agent is to sell is decided as follows:

$$
\mathrm{q}^{\mathrm{s}}(\mathrm{t})=\mathrm{s}(\mathrm{t})\left(\frac{\mathrm{m}_{\mathrm{t}}(\mathrm{h})-\mathrm{p}_{\mathrm{t}}^{+}}{\mathrm{m}_{\mathrm{t}}(\mathrm{h})}\right)
$$

The quantity that each agent is to buy is decided as follows:

$$
q^{b}(t)=\operatorname{int}\left\{\frac{c(t)\left(\frac{p_{t}^{-}-m_{t}(h)}{m_{t}(h)}\right)}{p_{t}}\right\}
$$

\subsection{Contrarian Traders}

The contrarian traders are structured simularly to the momentum traders except in their trading behaviour. A contrarian trader speculates that, if the stock price is rising, it will stop rising soon and decrease, so it is better to sell near the maximum, and vice versa. A gent sells if MA value: $\mathrm{m}_{\mathrm{t}}(\mathrm{h})=\frac{1}{\mathrm{~h}} \sum_{\mathrm{t}=\mathrm{t}-\mathrm{h}}^{\mathrm{t}-1} \mathrm{p}_{\mathrm{t}}$, computed with $\mathrm{h}$ time horizon is smaller than the price: $p_{t}^{+}=p_{t}+p_{t} \varepsilon$, where $\varepsilon \in(0,1)$ as input parameter. They will buy if the value of MA parameter is over the price: $\mathrm{p}_{\mathrm{t}}^{-}=\mathrm{p}_{\mathrm{t}}-\mathrm{p}_{\mathrm{t}} \varepsilon$.

\subsection{Fundamentalist Traders}

The fundamentalist trader believes that stocks have a fundamental value, like 1) earnings per share (EPS) and 2) price per earnings ratio (PIE), 3) economic characteristics of 
the firm's business (ECFB). They believe that, in the long run, the price of the stock will revert to its fundamental price. Consequently, they sell stocks if the price is higher than fundamental price and buy stocks in the opposite case.

In this section, we propose the BP neural network for fundamentalist traders of stock market, and its tuning method for improving the decision accuracy. In recent work, Xiumei Zhang, Chi Ma, Xinmiao Yu propose a neural network model for financial trend predicting, which is more accuracy when compare with China's existing institutions and financial website is [19].

The BP neural network is made by Rumelhant and McClelland in 1986, It is a typical multilayer feed-forward neural network [20]. Main existence shortcomings: slow learning speed, easy to fall into the local minimum. There is no theoretical guidance for the selection of the number of the hidden layer and elements. The BP neural network algorithm mainly consists of the forward propagation of the signal and the inverse of the error.

The BP neural network algorithm is mainly composed of two processes, which are the forward propagation of the signal and the reverse propagation of the error. In the forward propagation, the input sample is passed from the input layer, and the hidden layer is processed to the output layer after layer by layer. If the actual output of the output layer does not correspond to the expected output, the reverse transmission phase of the steering error is made. The reverse propagation of error is to output the error back to the input layer through the hidden layer. Each layer adjusts the weight and threshold according to the error signal, making the error between the output and expected output of the network gradually decrease until the accuracy requirement is met.

The structure of the three layer BP neural network is used in this paper. Its structure is shown in Figure 1.

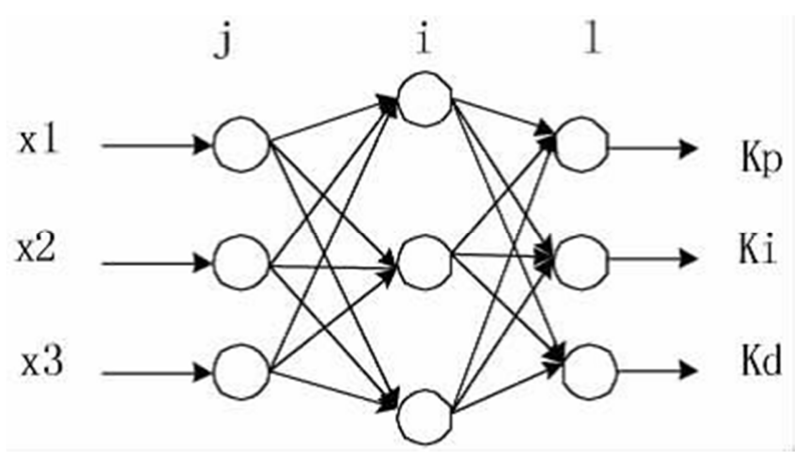

Figure 1. Three layer BP neural network structure.

The input of the network input layer is as follows:

$$
O^{(1)}(j)=X(j), j=1,2 \cdots M
$$

The number of input variables depends on the complexity of the system. The input and output of the hidden layer of the network are:

$$
n e t_{i}^{(2)}(k)=\sum_{j=1}^{M} \omega_{i j}^{(2)} O_{j}^{(1)}
$$

$$
O^{(2)}(k)=f\left(\operatorname{net}_{i}^{(2)}(k)\right), i=1,2 \cdots T
$$

Where $\omega_{i j}^{(2)}$ the hidden layer weighted coefficient; superscript (1), (2), (3) representing the input layer, hidden layer and output layer.

The function of the neurons of the hidden layer takes positive and negative symmetric Sigmoid functions:

$$
f(x)=\tanh (x)=\frac{e^{x}-e^{-x}}{e^{x}+e^{-x}}
$$

The output layer uses a linear function:

$$
\begin{gathered}
n e t_{i}^{(3)}(k)=\sum_{j=1}^{M} \omega_{i j}^{(3)} O_{j}^{(2)} \\
O^{(3)}(k)=a *\left(n e t_{i}^{(3)}(k)\right)+b
\end{gathered}
$$

Here $a, b$ is constant.

The BP algorithm is adopted to modify the weight, and the learning index function uses the sum of square sum of error.

If the actual output of step $\mathrm{K}$ is $O_{d}(k)$, the error function of the BP network can be expressed in the following form:

$$
E(k)=\frac{1}{2}\left(O_{d}(k)-O^{(3)}(k)\right)^{T}\left(O_{d}(k)-O^{(3)}(k)\right)
$$

In this article, there are 3 input variables, including earnings per share (EPS), price per earnings ratio (PIE) and economic characteristics of the firm's business (ECFB), will be used in the buying and selling rule.

The investor's transaction based on the numerical range of the output layer. The five transaction behaviours (STRONG BUY (STB), BUY (B), HOLD (HD), STRONG SELL (STS), SELL (S)) were adopted.

\subsection{Insiders Traders}

Insider is a trader who can get significant information in advance. It is well known that timely and accurate information is a crucial factor in the stock market. As a price sensitive event, the injection of liquidity into the market has been chosen, simulating open market operations of the central bank. Liquidity injection yields a higher price for shares. An insider agent, who knows in advance the date of this event, should be able to take in profits from this piece of insider information.

At the beginning of the simulation, each insider is given some liquidity $C_{i}(0)$ and no shares $S_{i}(0)$; at a given time t*, the global amount of cash is increased and the new cash is exchanged to security in few days. The cash inflow is distributed to agents proportionally to their total wealth.

The insider knows the timing and magnitude of the injection of liquidity in advance; let $r$ denote the number of periods by which his information is in the lead against other market participants; The insider is inactive for $\mathrm{t}<\mathrm{t}$ - $\mathrm{r}$ and acts as a fundamentalist trader knowing the new appropriate fundamental value, $\mathrm{p}\left(\mathrm{t}>\mathrm{t}^{*}\right)$, for $\mathrm{t}^{*}-\mathrm{r} \leq \mathrm{t}<\mathrm{t}^{*}$. This means that in this time period, the insider tries to convert all the cash 
into stocks. For $\mathrm{t}>\mathrm{t}^{*}$, the insider issues sell orders if the stock price is greater than the fundamental value $\mathrm{p}\left(\mathrm{t}>\mathrm{t}^{*}\right)$, otherwise he/she keeps its position.

\section{Market Clearing}

Suppose that at time $\mathrm{h}+1$ traders have issued $\mathrm{U}$ buy orders and $\mathrm{V}$ sell orders. For each buy order, let the pair $\left(\mathrm{q}_{\mathrm{u}}^{\mathrm{b}}, \mathrm{p}_{\mathrm{u}}^{\mathrm{b}}\right), \mathrm{u}=1,2, \cdots, \mathrm{U}$, indicate, respectively, the quantity of stocks to buy and the associated price. For each sell order in the same time step, let the pair $\left(\mathrm{q}_{\mathrm{v}}^{\mathrm{s}}, \mathrm{p}_{\mathrm{v}}^{\mathrm{s}}\right), \quad \mathrm{v}=1,2, \cdots, \mathrm{V}$ denote, respectively, the quantity of stocks to sell and the associated price.

Suppose that the inequality is satisfied as follows:

$$
\begin{gathered}
\mathrm{p}_{1}^{\mathrm{b}} \geq \mathrm{p}_{2}^{\mathrm{b}} \geq \cdots \geq \mathrm{p}_{\mathrm{U}}^{\mathrm{b}}, \\
\mathrm{p}_{1}^{\mathrm{s}} \leq \mathrm{p}_{2}^{\mathrm{s}} \leq \cdots \leq \mathrm{p}_{\mathrm{V}}^{\mathrm{s}}
\end{gathered}
$$

Define the clearing quantity of stocks:

$$
\mathrm{q}^{*}=\min \left\{\sum_{\mathrm{u}=1}^{\mathrm{U}} \mathrm{q}_{\mathrm{u}}^{\mathrm{b}}, \sum_{\mathrm{v}=1}^{\mathrm{v}} \mathrm{q}_{\mathrm{v}}^{\mathrm{s}}\right\}
$$

We simulate real market price mechanism: if $\mathrm{p}_{1}^{\mathrm{b}} \geq \mathrm{p}_{1}^{\mathrm{s}}$, trade is executed by $\mathrm{p}_{1}^{*}=\mathrm{p}_{1}^{\mathrm{s}}, \mathrm{q}_{1}{ }^{*}=\min \left\{\mathrm{q}_{1}^{\mathrm{b}}, \mathrm{q}_{1}^{\mathrm{s}}\right\}$; if $\mathrm{p}_{1}^{\mathrm{b}} \leq \mathrm{p}_{1}^{\mathrm{s}}$, trade is executed by

$$
\mathrm{p}_{1}^{*}=\frac{\mathrm{q}_{1}^{\mathrm{s}}}{\mathrm{q}_{1}^{\mathrm{b}}+\mathrm{q}_{1}^{\mathrm{s}}} \mathrm{p}_{1}^{\mathrm{b}}+\frac{\mathrm{q}_{1}^{\mathrm{b}}}{\mathrm{q}_{1}^{\mathrm{b}}+\mathrm{q}_{1}^{\mathrm{s}}} \mathrm{p}_{1}^{\mathrm{s}},
$$

$\mathrm{q}_{1}^{*}=\min \left\{\mathrm{q}_{1}^{\mathrm{b}}, \mathrm{q}_{1}^{\mathrm{s}}\right\}$. Similarly, we get clearing price $\mathrm{p}_{\mathrm{i}}^{*}$ according to rule ahead in order. It is necessary to note that if $\mathrm{q}_{1}^{\mathrm{b}} \leq \mathrm{q}_{1}^{\mathrm{s}}$, we compare $\mathrm{p}_{1}^{\mathrm{s}}$ with $\mathrm{p}_{2}^{\mathrm{b}}$ and vice versa. This process is operated until quantity clearing. The clearing price computed by the system is the $\mathrm{p}_{\mathrm{i}}^{*}$ at which the quantity clearing is satisfied. We define the new market price at time step $\mathrm{h}+1, \mathrm{p}(\mathrm{h}+1)=\mathrm{p}^{*}$. Following transactions, traders' cash and portfolio are updated. Orders that do not match the clearing price are discarded.

\section{Simulating}

\section{A. Parameter setup}

We can see table 1 showing the value of variables used at the beginning of the simulations.

Table 1. Parameter value.

\begin{tabular}{ll}
\hline Parameters & Value \\
\hline Number of agents ( N ) & 10,000 \\
Stock owned by each agent except insiders & 100 \\
Money owned by each agent & $\$ 2000$ \\
price each stock & $\$ 10$ \\
Number of iteration & 10000 \\
Agent Prob To Act for random trader & 0.2 \\
horizon for chartist trader & 20 \\
$\varepsilon$ & 0.01 \\
$r$ & 700 \\
net earnings of firm & 2000000 \\
timing of injection of liquidity & 1800 \\
magnitude of injection of liquidity & 1000000 \\
\hline
\end{tabular}

\section{B. Simulation Result}

We let the market run with 10000 agents, including 3800 random traders, 2000 chartist, 2000 contrarians, 2000 fundamentalists, 200 insiders. To give an idea of the timing involved, assume that a time step is of the order of a day. Then, 10,000 time steps correspond roughly to 40 years of market activity.

Figure 2 shows the price path, and a typical simulation for the logarithmic returns $r(t)=\log \frac{p(t)}{p(t-1)}$ can been seen from figure 3 and figure 4 . Large returns and cluster volatility are pointed out which suggest the presence of two stylized facts, i.e., fat tails and heteroscedasticity. Each population wealth curve is displayed from figure 5 to figure 9.

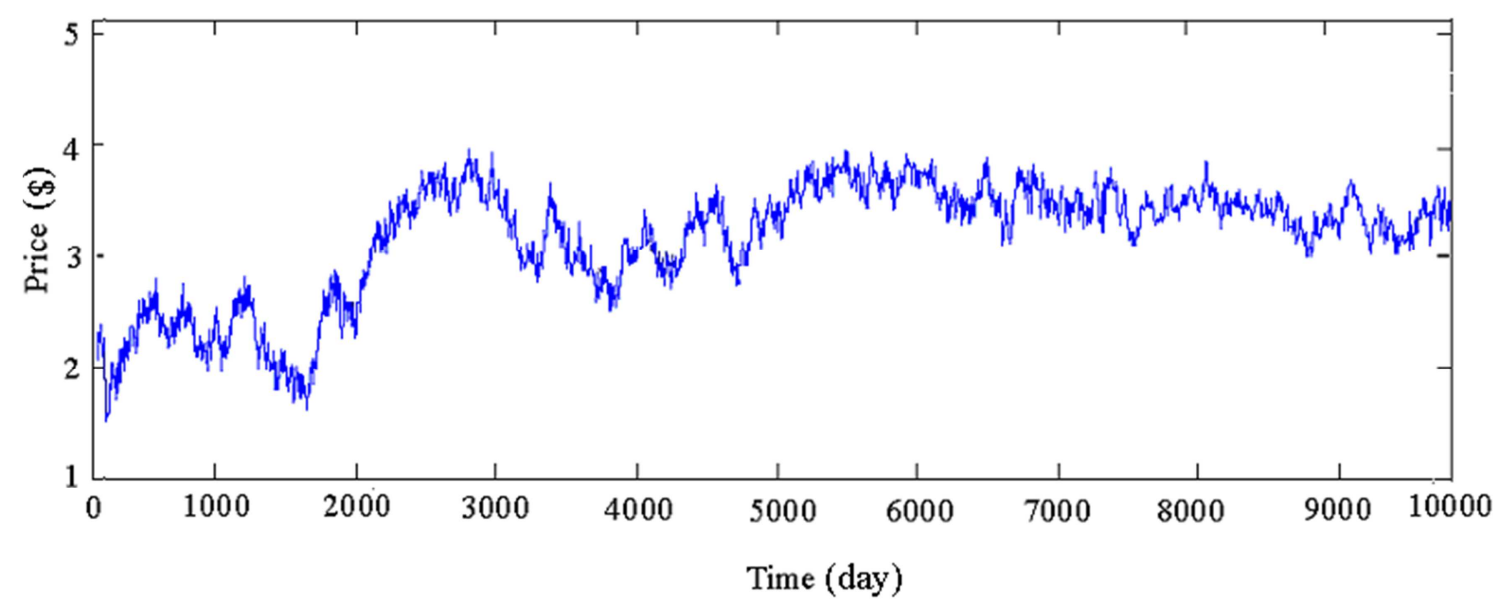

Figure 2. Daily time series for prices. 


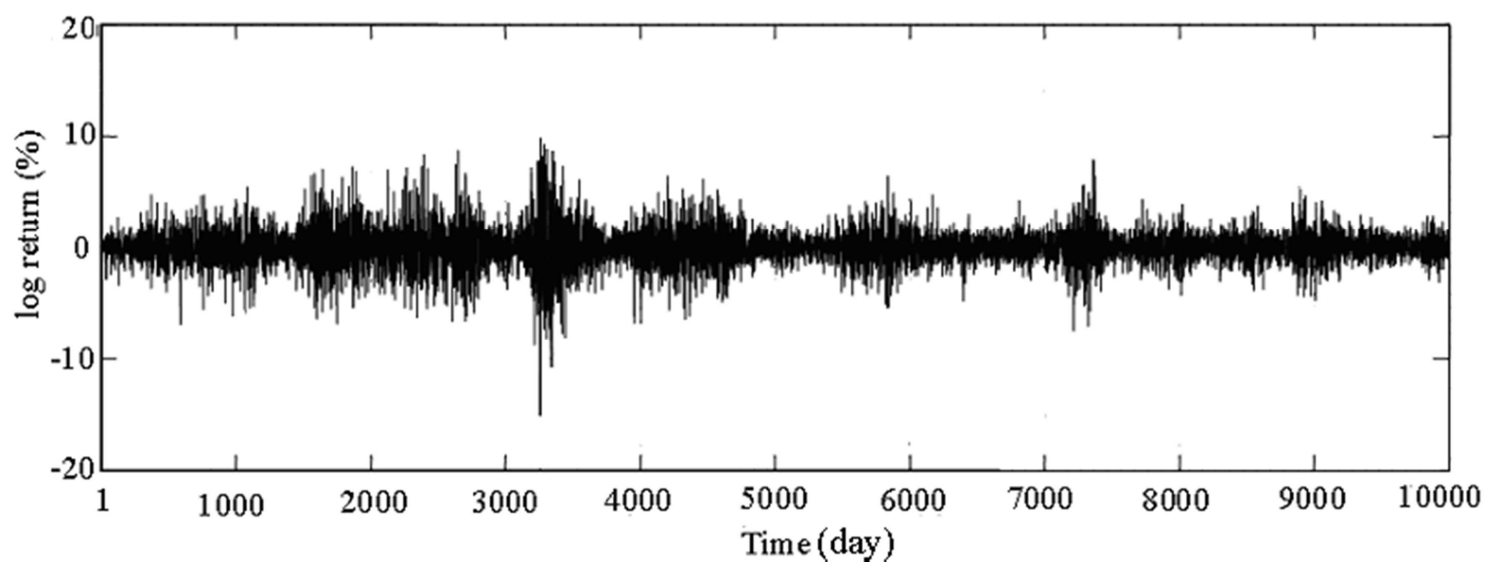

Figure 3. Daily time series for log returns.

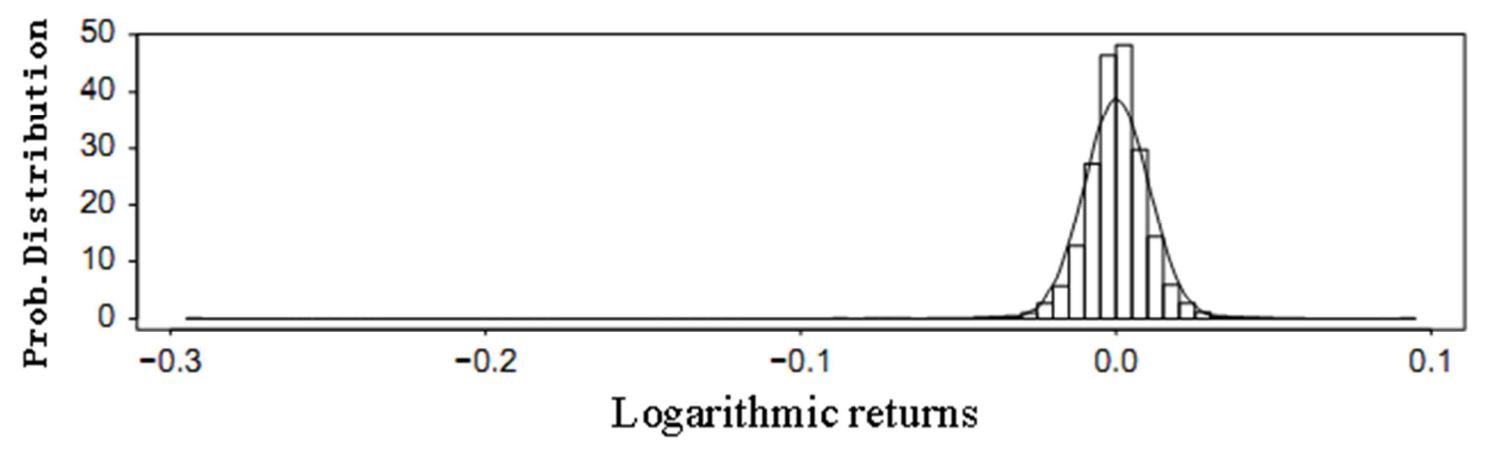

Figure 4. Logarithmic returns distribution histogram.

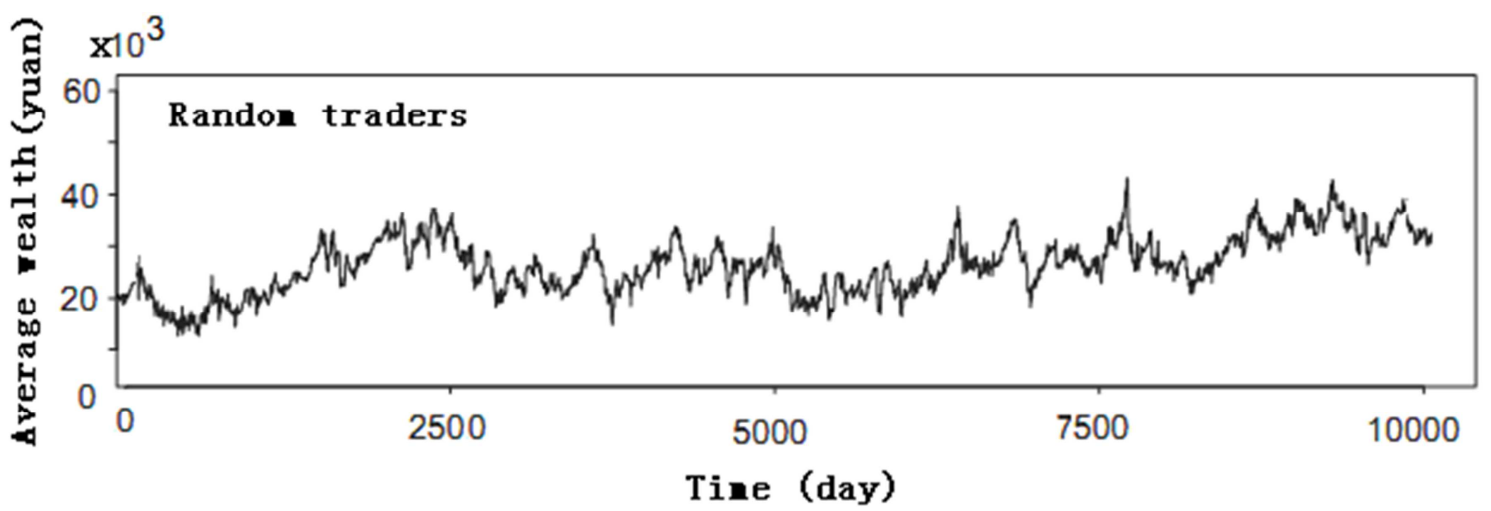

Figure 5. Average wealth change of random traders.

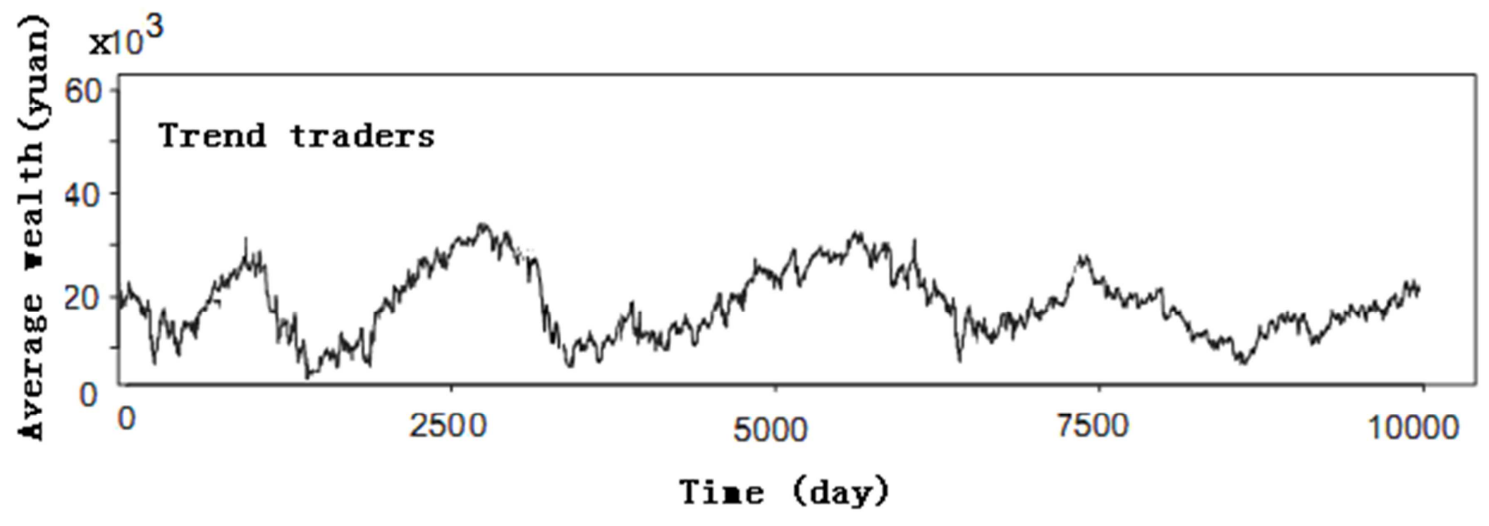

Figure 6. Average wealth change of trend traders. 


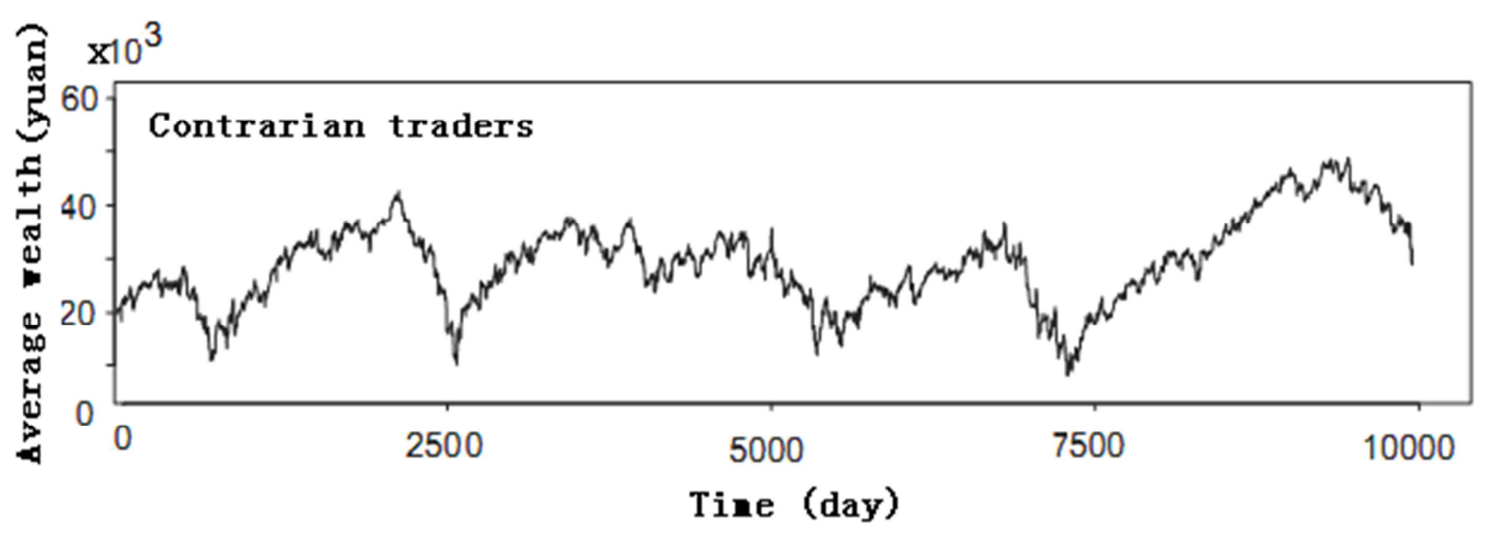

Figure 7. Average wealth change of contrarian traders.

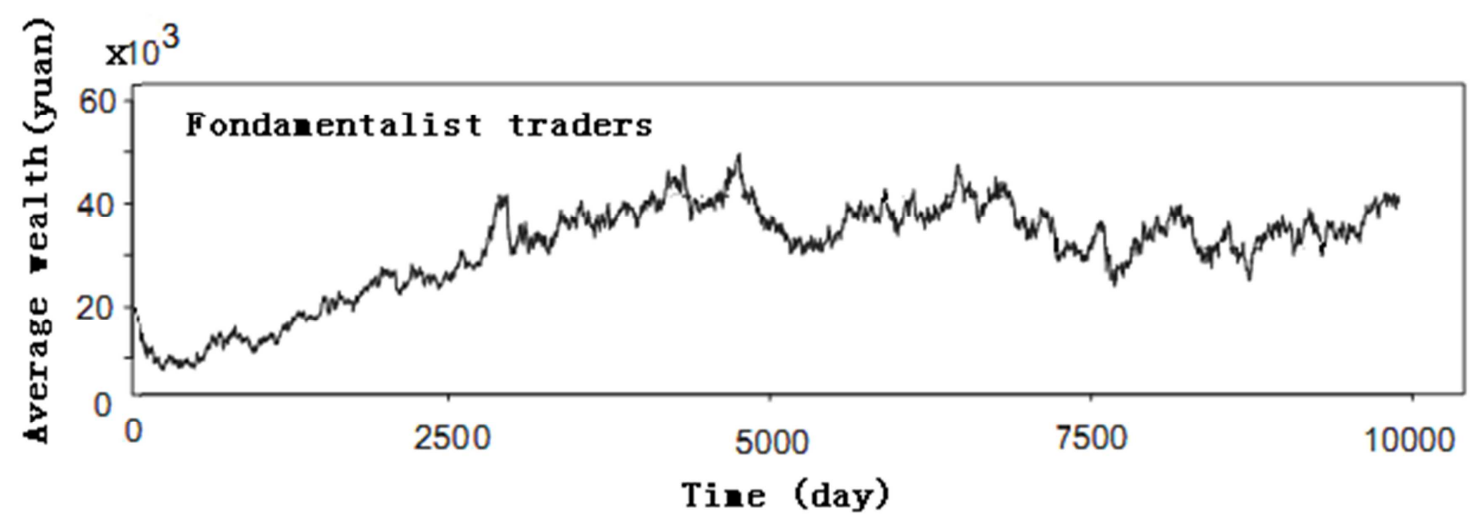

Figure 8. Average wealth change of fundamentalist traders.

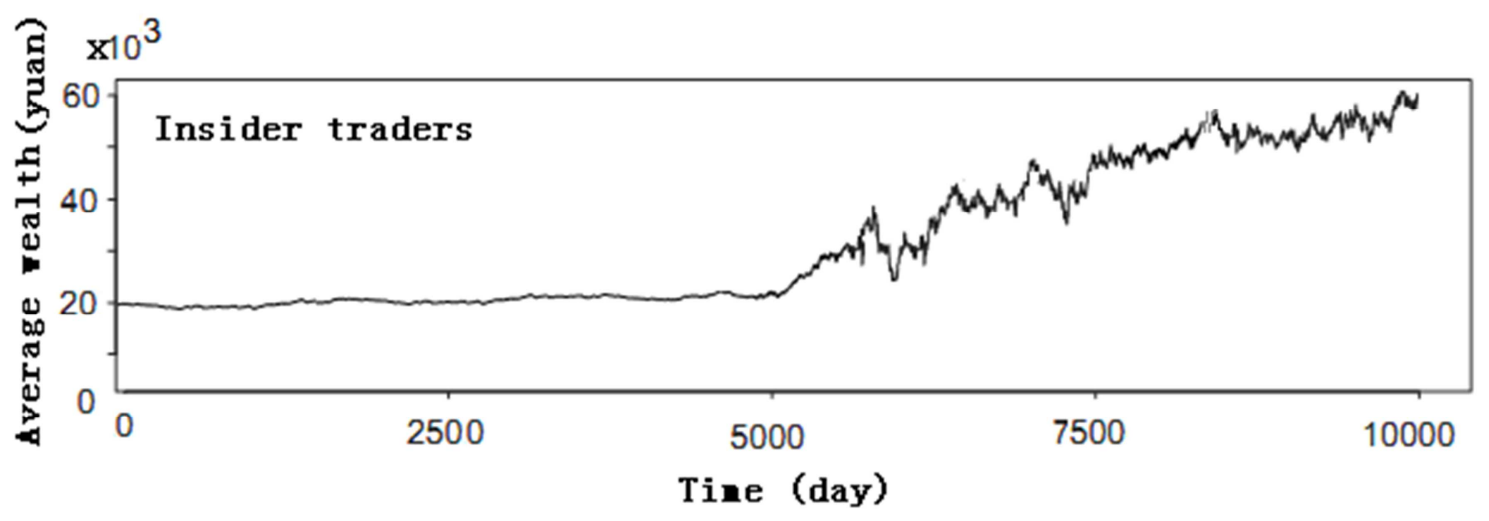

Figure 9. Average wealth change of insider traders.

See Figure 9, insiders, who know accurate timing and quantity of cash inflow, buy stocks before information is public and soon sell all stocks they own after information is known and retain only cash. Thus, the change in their cash and stock occurs because of the injection of cash. All other populations increase their cash or stocks according to each trading rule, but with different rates.

\section{Conclusion}

We discuss a simple artificial stock market with five different populations who interact with different trading strategies. A new clearing mechanism that matches price in order is mentioned. Simulation results show that trading strategies yield different results. It is noticeable that insiders can easily get more profit in short time due to prior information.

\section{References}

[1] John G. Mooney, V. G. a. K. L. K. A Process Oriented Framework for Assessing the Business Value of Information Technology. Forthcoming in the Proceedings of the Sixteenth Annual International Conference on Information Systems. 2001.

[2] Zhou, Qingyuan, Luo, Juan: The service quality evaluation of ecologic economy systems using simulation computing. Comput. Syst. Sci. Eng, 2016, 31 (6), pp: 453-460. 
[3] Zhou, Qingyuan, Luo, Jianjian: The study on evaluation method of urban network security in the big data era. Intell. Autom. Soft Comput. 2017, DOI:10.1080/10798587.2016.1267444.

[4] Jian Yang. The artificial stock market model based on agent and scale-free network. Cluster Comput, 2017, DOI 10.1007/s10586-017-0991-4.

[5] Assenza T, Delli Gatti D, Grazzini J. Emergent dynamics of a macroeconomic agent based model with capital and credit. Journal of Economic Dynamics and Control, 2015, 50, pp:528 .

[6] Cipriani, M., \& Guarino, A.. Estimating a structural model of herd behavior in financial markets. American Economic Review, 2014, 104 (1), 224-51.

[7] Hazem Krichene Mhamed-Ali El-Aroui, Agent-Based Simulation and Microstructure Modeling of Immature Stock Markets, Comput Econ, 2018, 51, pp:493-511, https://doi.org/10.1007/s10614-016-9615-y.

[8] Tedeschi, G., Iori, G., \& Gallegati, M.. Herding effects in order driven markets: The rise and fall of gurus. Journal of Economic Behavior and Organization, 2012, 81, pp: 82-96.

[9] Mizuta, T., Izumi, K., Yagi, I., \& Yoshimura, S. Investigation of price variation limits, short selling regulation, and uptick rules and their optimal design by artificial market simulations. Electronics and Communications in Japan, 2015, 98 (7), pp: $13-21$.

[10] Xuan Zhou Honggang Li, Buying on Margin and Short Selling in an Artificial, Comput Econ, 2017, DOI 10.1007/s10614-017-9722-4.

[11] Anand, K., Kirman, A., \& Marsili, M.. Epidemics of rules, rational negligence and market crashes, The European Journal of Finance, 2013, 19 (5), 438-447.
[12] Arajo, RdA, Oliveira, A. L. I., Meira, S.: A hybrid model for high-frequency stock market forecasting. Expert Systems with. Applications, 2015, 42, pp: 4081-4096.

[13] Hafezi, R., Shahrabib, J., Hadavandi, E.: A bat-neural network multi-agent system (BNNMAS) for stock price prediction: case study of DAX stock price. Appl. Soft Comput. 2015, 29, pp: 196-210.

[14] Kawakubo S, Izumi K, Yoshimura S, Analysis of an option market dynamics based on a heterogeneous agent model. Intell Syst Acc Finance Manag, 2014, 21 (2), pp: 105-128.

[15] Xu HC, Zhang W, Xiong X, Zhou WX, An agent-based computational model for china's stock market and stock index futures market. Mathematical Problems in Engineering, 2014, Article ID: 563912.

[16] Bollerslev $\mathrm{T}$ Generalised Autoregressive Conditional Heteroscedasticity. Journal of Econometrics, 1986, 31, pp: 307-327.

[17] Cont R. Empirical properties of asset returns: stylized facts and statistical issues. Quantitative Finance, 2001, 1, pp: 223-236.

[18] Shao Yanhua, LI Jianshi and WANG Jinghong. Model and Simulation of Stock Market Based on Agent. Proceedings of the 2008 IEEE International Conference on Information and Automation June 20-23, 2008, Zhangjiajie, China, 248-252.

[19] Xiumei Zhang, Chi Ma, Xinmiao Yu, A neural network model for financial trend predicting, Cluster Computing, 2018, https://doi.org/10.1007/s10586-018-2196-x.

[20] Wang, X., Wang, H., Wang, W. H.: Artificial neural network theory and applications. Northeastern University Press, Shenyang (2000). 